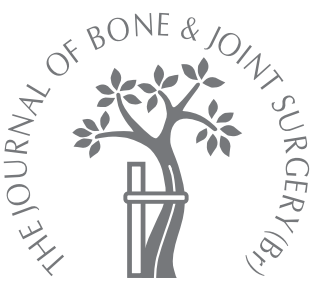

- REVIEW ARTICLE

\title{
Bone-turnover markers in fracture healing
}

G. Cox,

T. A. Einhorn,

C. Tzioupis,

P. V. Giannoudis

From Leeds General

Infirmary, Leeds, England
G. Cox, BMBS, MRCS,

Research Fellow

- C. Tzioupis, MD, Trauma

Fellow

P. V. Giannoudis, MD, FRCS,

Professor

Academic Unit, Trauma and

Orthopaedic Surgery,

Clarendon Wing

Leeds General Infirmary, Great George Street, Leeds LS1 3EX, UK.

- T. A. Einhorn, MD, Professor and Chairman

Department of Orthopaedic Surgery

Boston University Medical Centre, 720 Harrison Avenue, DOB 808, Boston,

Massachusetts, USA.

Correspondence should be sent to Professor P. V. Giannoudis; email: pgiannoudi@aol.com

(일 British Editorial Society of Bone and Joint Surgery doi:10.1302/0301-620X.92B3. $22787 \$ 2.00$

$J$ Bone Joint Surg [Br] 2010;92-B:329-34.

Biochemical markers of bone-turnover have long been used to complement the radiological assessment of patients with metabolic bone disease. Their implementation in daily clinical practice has been helpful in the understanding of the pathogenesis of osteoporosis, the selection of the optimal dose and the understanding of the progression of the onset and resolution of treatment. Since they are derived from both cortical and trabecular bone, they reflect the metabolic activity of the entire skeleton rather than that of individual cells or the process of mineralisation.

Quantitative changes in skeletal-turnover can be assessed easily and non-invasively by the measurement of bone-turnover markers. They are commonly subdivided into three categories; 1) bone-resorption markers, 2) osteoclast regulatory proteins and 3) boneformation markers. Because of the rapidly accumulating new knowledge of bone matrix biochemistry, attempts have been made to use them in the interpretation and characterisation of various stages of the healing of fractures. Early knowledge of the individual progress of a fracture could help to avoid delayed or nonunion by enabling modification of the host's biological response.

The levels of bone-turnover markers vary throughout the course of fracture repair with their rates of change being dependent on the size of the fracture and the time that it will take to heal. However, their short-term biological variability, the relatively low bone specificity exerted, given that the production and destruction of collagen is not limited to bone, as well as the influence of the host's metabolism on their concentration, produce considerable intra- and inter-individual variability in their interpretation. Despite this, the possible role of bone-turnover markers in the assessment of progression to union, the risks of delayed or nonunion and the impact of innovations to accelerate fracture healing must not be ignored.

Bone as a living, dynamic tissue undergoes daily anabolic and catabolic turnover through the action of the basic multicellular units of osteoblasts and osteoclasts. This turnover can be demonstrated by measuring the presence of a number of molecular markers which suggest the amount of formation (osteoblastic activity) or resorption (osteoclastic activity) of bone which is occurring. These 'boneturnover markers' (BTMs) are commonly subdivided into three categories: 1) boneresorption markers, 2) osteoclast regulatory proteins and 3) bone-formation markers. ${ }^{1-3}$ During the normal homeostasis of bone, formation and resorption are balanced and this varies throughout life. In childhood and adolescence bone formation exceeds resorption, but this situation is reversed in later life. However, the balance can be lost in pathological conditions. Changes in BTMs are well known in metabolic conditions such as osteoporosis ${ }^{2,4,5}$ and Paget's disease, ${ }^{6}$ but are less well described in the healing of fractures.

Bone-resorption markers can be collagenous or non-collagenous. The former measure the degradation of type-I collagen and include peptide fragments such as the C-telopeptide of type-I collagen (CTX) ${ }^{7,8}$ the $\mathrm{N}$-telopeptide of type-I collagen (NTX), ${ }^{9}$ the carboxy-terminal telopeptide of type-I collagen (ICTP) $)^{10-13}$ and pyridinoline and deoxypyridinoline. ${ }^{14,15}$ Noncollagenous bone resorption markers include the enzymes tartrate-resistant acid phosphatase (TRAcP) ${ }^{11}$ and cathepsin K. ${ }^{16,17}$ The latter is the primary acid hydrolase responsible for bone resorption. Regulation of osteoclastic activity is controlled by factors which drive the fusion of mononuclear osteoclast precursors to form mature multinucleated osteoclasts. These factors include receptor activator of nuclear 
Table I. Markers of bone resorption osteoclast regulatory proteins and their activity in fracture healing

\begin{tabular}{|c|c|c|}
\hline Bone-resorption markers & Source/action & Marker activity in fracture healing \\
\hline CTX & $\begin{array}{l}8 \text { amino-acid fragment from } \mathrm{C} \text {-telopeptide of } \\
\text { type-I collagen } \\
\text { Generated by cathepsin-K activity }{ }^{7}\end{array}$ & $\begin{array}{l}\text { Rises first week after fracture of the tibial shaft and } \\
\text { remains elevated throughout fracture healing }\end{array}$ \\
\hline NTX & $\begin{array}{l}8 \text { amino-acid fragment from } \mathrm{N} \text {-telopeptide of } \\
\text { type-I collagen } \\
\text { Generated by cathepsin-K activity }{ }^{9}\end{array}$ & Not been investigated in fracture healing \\
\hline ICTP & $\begin{array}{l}\text { Carboxy-terminal telopeptide of type-I collagen } \\
\text { Released by matrix metalloproteinase }{ }^{10} \\
\text { Eradicated by cathepsin K activity }\end{array}$ & $\begin{array}{l}\text { Rises first week after fracture of the tibial shaft and } \\
\text { remains elevated throughout healing }{ }^{11-13}\end{array}$ \\
\hline PYD & $\begin{array}{l}\text { Form cross-links between mature collagen } \\
\text { polypeptides }\end{array}$ & $\begin{array}{l}\text { Peaks } 1 \text { to } 4 \text { weeks after fracture of the tibial shaft, }{ }^{14} \\
1 \text { to } 8 \text { weeks after proximal femoral fracture }{ }^{15}\end{array}$ \\
\hline DPD & $\begin{array}{l}\text { Form cross-links between mature collagen } \\
\text { polypeptides }\end{array}$ & Peaks 1 to 8 weeks after proximal femoral fracture ${ }^{15}$ \\
\hline \multicolumn{3}{|c|}{ Osteoclast regulatory proteins } \\
\hline RANKL & $\begin{array}{l}\text { Member of tumour-necrosis family, produced by } \\
\text { osteoblasts and activated by T lymphocytes }\end{array}$ & Not been investigated in fracture healing \\
\hline OPG & $\begin{array}{l}\text { Secreted by osteoblasts as a decoy-receptor to } \\
\text { bind to RANKL. Down-regulates osteoclast } \\
\text { activation and proliferation }\end{array}$ & Not been investigated in fracture healing \\
\hline TRAcP & $\begin{array}{l}\text { Glycoprotein produced by osteoclasts and acti- } \\
\text { vated by macrophages/dendritic cells. Acts as } \\
\text { phosphatase and generator of oxygen-free } \\
\text { radicals }\end{array}$ & $\begin{array}{l}\text { Peaks at } 7 \text { days after osteosynthesis in ankle } \\
\text { fractures and } 2 \text { weeks in tibial fractures }{ }^{11}\end{array}$ \\
\hline Cathepsin-K & Cysteine protease produced by osteoclasts & Not been investigated in fracture healing \\
\hline
\end{tabular}

Table II. Markers of bone formation and their activity in fracture healing

\begin{tabular}{|c|c|c|}
\hline Bone-formation markers & Source/action & Marker activity in fracture healing \\
\hline PIIINP & $\begin{array}{l}\text { N-terminal peptide cleaved from type-III } \\
\text { procollagen when it forms type-III collagen }\end{array}$ & $\begin{array}{l}\text { Maximal levels at } 2 \text { weeks after ankle fracture and } \\
12 \text { weeks after fracture of the tibial shaft } \\
8,11-13\end{array}$ \\
\hline PICP & $\begin{array}{l}\text { C-terminal peptide cleaved from type-I } \\
\text { procollagen when it forms type-I collagen }\end{array}$ & $\begin{array}{l}\text { Peaks } 20 \text { to } 24 \text { weeks after fracture of the tibial } \\
\text { shaft }{ }^{11,13} \text { Peaks } 2 \text { weeks after distal radial fracture } \\
\text { remaining elevated at } 9 \text { months }{ }^{24}\end{array}$ \\
\hline PINP & $\begin{array}{l}\mathrm{N} \text {-terminal peptide cleaved from type-I } \\
\text { procollagen when it forms type-I collagen }\end{array}$ & $\begin{array}{l}\text { Maximal at } 12 \text { weeks after fracture of the tibial shaft } \\
\text { remaining elevated at } 24 \text { weeks. }{ }^{8} \text { Similar results with } \\
\text { proximal femoral fractures }{ }^{15}\end{array}$ \\
\hline OC & $\begin{array}{l}\text { Main non-collagenous protein produced by } \\
\text { osteoblasts }\end{array}$ & $\begin{array}{l}\text { Elevated at } 24 \text { weeks after fracture of the tibial } \\
\text { shaft }{ }^{8,11} \text { Elevated } 1 \text { week after distal radial fracture }\end{array}$ \\
\hline BSAP & $\begin{array}{l}\text { Isoenzyme produced by osteoblasts involved } \\
\text { with calcification of skeleton and bone forma- } \\
\text { tion }\end{array}$ & $\begin{array}{l}\text { Increased at } 4 \text { weeks after fracture of the tibial } \\
\text { shaft. }{ }^{8,11,14,25} \text { Remains elevated at } 1 \text { year }{ }^{14}\end{array}$ \\
\hline
\end{tabular}

factor NF-kB ligand (RANKL) $)^{18-20}$ and the c-fms protooncogene. ${ }^{21}$ Modulation of osteoclastic activity is controlled by the decoy receptor, osteoprotegerin (OPG) (Table I). ${ }^{22,23}$

Bone-formation markers are indicative of osteoblastic activity. Although type-III collagen, a non-osteoblastic protein, is the initial collagen laid down during the healing of fractures, it is replaced by type-I collagen when bone formation begins. ${ }^{24}$ Hence, markers of bone healing include fragments of type-I and type-III procollagen released during the formation of type-III collagen (type-III collagen Nterminal propeptide, PIIINP), ${ }^{8,11-13}$ type-I collagen (type-I collagen C-terminal propeptide, PICP) $)^{11,13,25}$ and type-I collagen N-terminal propeptide (PINP). ${ }^{8,15}$ More specific measures of osteoblastic activity include osteocalcin, ${ }^{8,11,25}$ the major non-collagenous protein of bone matrix, ${ }^{3}$ and the isoenzyme bone-specific alkaline phosphatase (BSAP)
(Table II). ${ }^{8,11,14,26}$ Figure 1 gives an overview of BTM activity in the healing of fractures.

An understanding of the changes in the BTMs during fracture repair is of interest since potentially this could lead to the development of new methods of assessing the progression of a fracture to union. Indeed, while radiographs are currently the most useful tool for following the healing of a fracture, the ability to detect the elaboration of specific molecular markers of cellular activity could enhance the accuracy of the assessment of healing and allow the early detection of fractures at risk of nonunion. The use of BTMs may be of particular interest given the recent innovations designed to accelerate fracture healing, such as the use of bone morphogenetic proteins (BMPs) and the development of other local and systemic treatments. ${ }^{27-31}$ Changes in the blood levels of BTMs could provide a mechanism for measuring the effects of these treatments and thus enhance the 


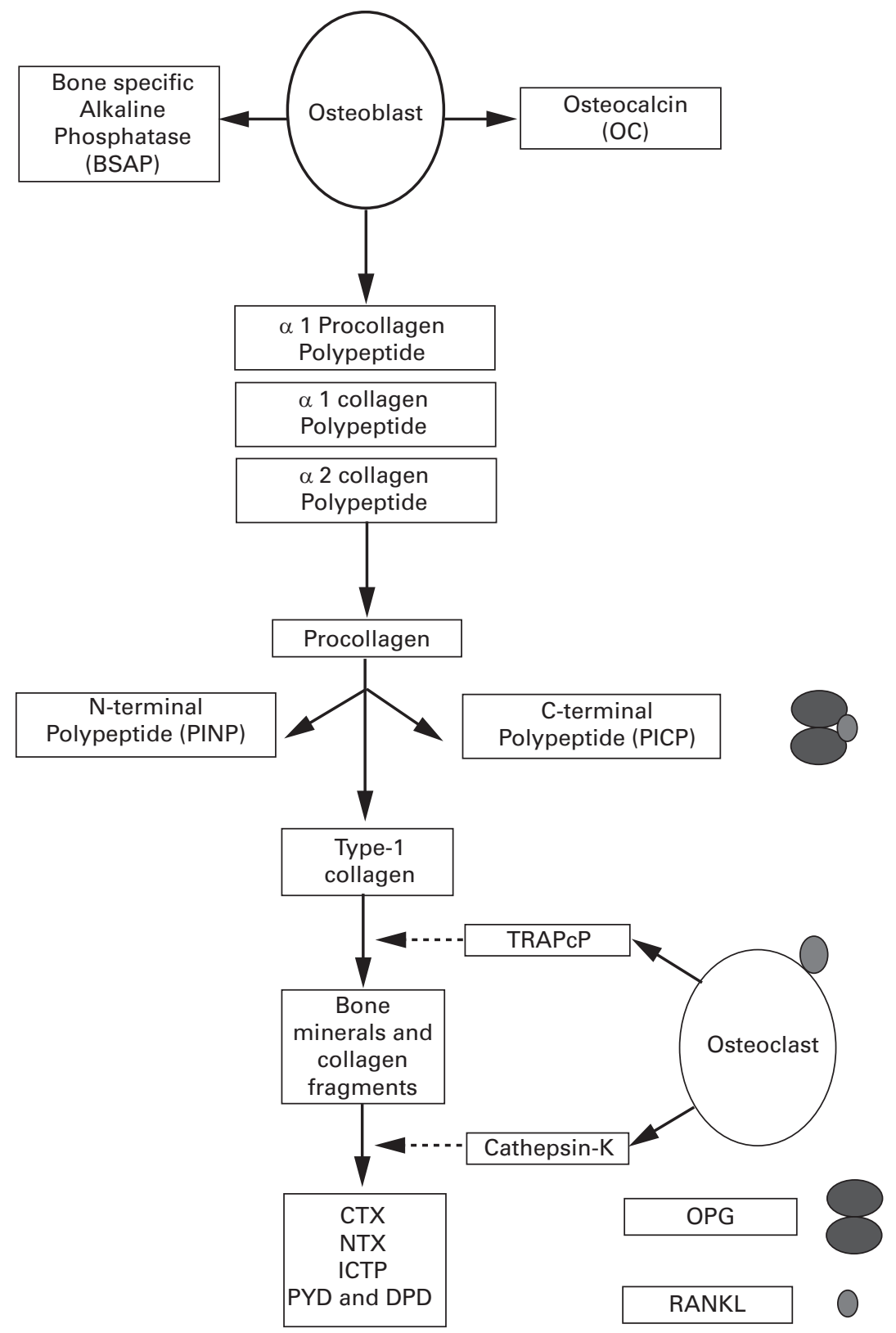

Fig. 1

Diagram showing osteoblastic activity producing BSAP, osteocalcin and type-I procollagen. Procollagen has PINP and PICP molecules cleaved off to form type-I collagen. RANKL and OPG are secreted by osteoblasts. RANKL upregulates osteoclastic activity and OPG acts as a soluble decoy molecule binding to RANKL and hence causing downregulation. Osteoclasts, once activated by RANKL, secrete TRAcP which cleaves type-I collagen into fragments.

detection of the beneficial effects of such interventions during clinical trials.

\section{Bone-turnover markers in the repair of fractures}

The levels of BTMs vary throughout the course of fracture repair with their rates of change being dependent on the nature of the fracture and the time which it takes to heal..$^{8,11,25}$ The type and location of a fracture may also affect the expression of BTMs with diaphyseal tibial frac- tures taking longer to progress through the cycle of repair than ankle ${ }^{8,11}$ or distal radial fractures. ${ }^{25}$ Similarly, the amplitude of the BTM curve varies with the extent of the fracture, with levels of BTMs being higher in tibial fractures than in those of the ankle, ${ }^{11}$ hip and wrist (Fig. 2). ${ }^{32}$

Bone-resorption markers. Fracture stimulates an increase in the number and activity of bone metabolic units and, initially, there is a net loss of bone as resorption exceeds formation. ${ }^{33}$ This is partly due to the traumatic process itself, 


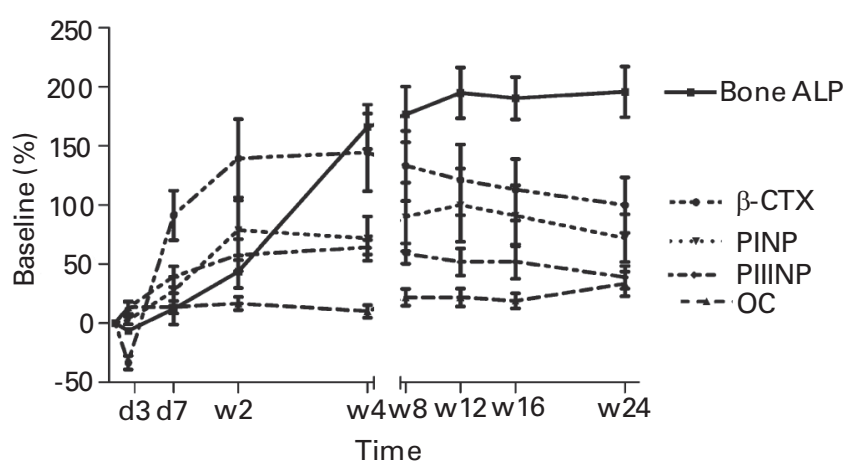

Fig. 2

Graph showing the variation in bone markers after tibial fracture. Reproduced with kind permission of Springer Science and Business Media from Veitch SW, Findlay AJ, Hamer AJ, et al. Changes in bone mass and bone turnover following tibial shaft fracture. Osteoporosis Int 2006; 17:364-72.

but may also be associated with immobility since this stimulates resorption and inhibits bone formation. ${ }^{34}$

Veitch et $a l^{8}$ found that the level of CTX- $\beta$ had increased at three days after fracture in patients with fractures of the tibial shaft and that it continued to rise over two weeks with levels remaining elevated at 24 weeks. Stoffel et $\mathrm{al}^{11}$ found similar results with the ICTP marker. Other studies have found comparable results. ${ }^{12,13}$ The levels of pyridinoline have been shown to peak one to four weeks after fracture of the tibial shaft before falling to immediate postinjury levels at 26 weeks. ${ }^{14}$ Pyridinium crosslinks and the levels of pyridinoline and deoxypyridinoline peak one to eight weeks after fracture in proximal femoral fractures. ${ }^{15}$ It is of note that most of these studies lasted only 24 weeks at which time the degradation products of type-I collagen were generally still elevated. ${ }^{8,11}$

Non-collagenous bone-resorption markers have been less well investigated. Levels of TRAcP 5 b peak seven days after osteosynthesis in ankle fractures and after two weeks in tibial fractures, remaining high at 24 weeks. ${ }^{11}$ The variation in cathepsin- $\mathrm{K}$ in this setting is unknown.

Osteoclast regulatory proteins. This group of BTMs has not been extensively investigated with regard to healthy patients with a fracture and to our knowledge variations in OPG and RANKL have not been recorded after fractures. ${ }^{35-38}$

Bone-formation markers. Inhibition of osteoblast synthesis occurs after fracture with studies showing decreased levels of $\mathrm{BSAP}^{11,26}$ and $\mathrm{PICP}^{11,13}$ in the immediate post-fracture period. Increased levels of osteocalcin have been reported at this stage $\mathrm{e}^{11,14,26}$ and it is hypothesised that this represents a release of osteocalcin from its bone-bound form through osteoclastic activity.

Stoffel et $\mathrm{al}^{11}$ found levels of PIIINP to be the first marker of synthesis to become elevated during fracture healing, reaching a maximum after two weeks in ankle fractures and at 12 weeks in tibial fractures, then becoming normal before radiological union. Other studies have found similar values $^{8,12,13}$ although not all show a normalisation of the levels with repair of the fracture. ${ }^{8,12,13}$ Levels in distal radial fractures were found to become elevated one week after injury and remained high throughout treatment. ${ }^{24}$

PINP has been shown to rise after a fracture of the tibial shaft to a maximum level at week 12 and to remain elevated until week $24 .^{8}$ Similar results have also been found in studies of proximal femoral fractures. ${ }^{15,31}$ PICP has also been shown to increase after an initial fall after fracture of the tibial shaft to a peak at 20 to 24 weeks. ${ }^{11,13}$ One study showed this to occur at only two weeks after a fracture. ${ }^{12}$ Levels of PICP in distal radial fractures have been reported to become elevated by two weeks after injury and to remain high at nine months. ${ }^{25}$

Levels of osteocalcin have been shown to rise, following an initial fall, after fracture of the tibial shaft with higher levels occurring at 24 weeks. ${ }^{8,11}$ Elevated levels of this were seen after one week in distal radial fractures before levelling off at nine months. ${ }^{24} \mathrm{~A}$ smaller rise than expected in osteocalcin was found by one study, suggesting that this was secondary to inhibition by cortisol, which is secreted as a stress response. ${ }^{8}$

BSAP has been shown to increase at approximately four weeks after tibial fracture $8,11,14,26$ and to remain elevated during treatment for up to one year. ${ }^{14}$ Emami et al $^{14}$ found lower levels of BSAP in patients with delayed healing after intramedullary nailing of tibial fractures at four to seven weeks compared with patients in whom their fractures progressed to union.

\section{Delayed or nonunion}

The changes in levels of BTM and their ability to predict delayed or nonunion have been considered by several authors, but it appears that no consensus has been reached. A decreased level of BSAP in the early stages of healing has been reported. ${ }^{14}$ Others, however, have shown that it is initially increased, ${ }^{11,39}$ followed by a subsequent decline at 14 to 20 weeks. ${ }^{13}$ Compared with normal healing, some studies have suggested that the peak of osteocalcin occurs later in cases of delayed union, ${ }^{14,39,40}$ but others do not support these findings. ${ }^{8,11}$ A fall in the level of PICP at 14 to 20 weeks, and elevated levels of PIIINP in early healing at five to ten weeks, have also been suggested as markers for delayed union. ${ }^{13}$

\section{Sampling}

Collagenous markers of bone resorption have circadian variation with peaks in the early hours of the morning and a trough during the day. ${ }^{41,42}$ This is independent of gender, age, menopausal status, mobility and secretion of pituitary hormones $^{43}$ and has been hypothesised to be secondary to food intake, possibly involving endogenous secretion of glucagon-like peptide $2 .{ }^{44}$ In order to obtain valid results it is therefore necessary that sampling should be undertaken in a fasting state within a limited period. Interindividual variation is high when comparing BTMs ${ }^{13,14,40,45}$ and this 
has led to the use of intra-individual differences rather than pooled mean numbers in studies. ${ }^{39}$ Individual levels of BTMs have also been shown to vary over time with factors such as dietary habit, smoking, exercise and medication being implicated. ${ }^{2,46}$

\section{Assays}

Assays for many BTMs have been successfully automated after growing interest in these as measures of effectiveness and compliance in the treatment of osteoporosis. ${ }^{47}$ This development has allowed the rapid measurement of BTMs outside the research laboratory with the potential for these markers to be incorporated into clinical practice if found to be useful.

\section{Discussion}

All studies have shown a similar picture of the variations in BTMs with fracture healing. There is an initial net loss of bone, with elevated collagenous degradation products and osteoclast regulatory proteins, with a corresponding decrease in bone formation markers. This is followed by an increase in these markers, led initially by products from the formation of type-III and then type-I collagen. Resorption markers peak earlier than formation markers and are generally found to remain elevated even after union, presumably secondary to ongoing remodelling. The rate of change and the quantity of bone marker produced are dependent on the size of the fracture with larger fractures taking longer to move through the repair cycle and with larger amounts of BTMs being released.

Many of the studies investigating BTMs during fracture healing have low statistical power with only 18 to 30 patients being included. ${ }^{8,11,13-15,39}$ This weakens the quality of the evidence. While one study included a larger number of patients, their heterogenous nature was a concern. ${ }^{32}$ Tibial fractures are the most frequently investigated injury of the long bone, which aids comparison between studies. However, these fractures have been treated using a number of strategies which impairs comparison between studies. ${ }^{8,11,14,39}$ Differences in the techniques of assay of BTMs remain a problem and their standardisation and agreement as to which should be used would improve the understanding of their validity in the assessment of fracture healing. The decision of some authors to use pooled mean values ${ }^{11,13,14}$ and others to use intra-individual changes ${ }^{39}$ has further complicated comparisons. Only one study has reported a baseline level of BTM before fracture $^{32}$ and most other reports have used a non-fasting baseline for measurements made at varying times after fracture. This represents an uncontrolled variable since such samples are most likely to be influenced by early biochemical changes resulting from the injury and may also be susceptible to circadian variations. It is of note that some BTMs in use for the measurement of metabolic bone disease have not been investigated in fracture healing and this represents potential for further study.
Most investigations have been carried out for only 24 weeks or less. ${ }^{8,11,13,15}$ Although union was generally achieved, markers of both resorption and formation remained elevated. A better design of study would follow the levels until they returned to baseline in fractures which united. This would provide more comprehensive information regarding the role of assessment of these markers during healing and the usefulness of such measurements in the detection of impaired healing.

It is difficult to reach a conclusion regarding BTMs and the prediction of delayed or nonunion. This is partly because of a lack of consensus of the varying reports and to the lack of robust statistical power. PIIINP shows promise as a marker of delayed union with some studies showing that it fell to normal levels before union ${ }^{11}$ and others showing high early levels which may imply that delayed union is likely. ${ }^{13}$ There may be a role for osteocalcin, BSAP or other BTMs in the prediction of delayed or nonunion, but better powered studies would be necessary to confirm this. One report has shown an earlier fall in transforming growth factor- $\beta 1$ in delayed long-bone diaphyseal fracture healing. This study involved an experimental design of ten matched patients in each group. ${ }^{48}$

The changes in BTMs after fracture reflect our understanding of the repair of a fracture through the cascade of inflammation and resorption, deposition of callus and remodelling. Inflammation and resorption are reflected by the initial elevation in collagenous degradation products and a corresponding decrease in bone-formation markers. Deposition of callus follows this with an increase in these markers. Remodelling is the final step in bone repair and is characterised by high levels of bone resorption and formation markers.

Current information does not encourage the routine use of BTMs to assess the progression of a fracture to union, and the ability to measure interventions designed to accelerate fracture healing has not been established as yet. However, further research is warranted to assess their potential in this role. The tibial fracture appears to be a good model for further investigation, given the frequency of its presentation, the levels of BTM produced and its relatively frequent incidence of delayed or nonunion. Appropriately designed and sufficiently powered studies will be able to test the value of measuring BTMs and possibly support the routine investigation of BTM in patients with delayed union.

No benefits in any form have been received or will be received from a commercial party related directly or indirectly to the subject of this article.

\section{References}

1. Civitelli R, Armamento-Villareal R, Napoli N. Bone turnover markers: understanding their value in clinical trials and clinical practice. Osteoporos Int 2009;20:843-51

2. Leeming DJ, Alexandersen $\mathbf{P}$, Karsdal MA, et al. An update on biomarkers of bone turnover and their utility in biomedical research and clinical practice. Eur $\mathrm{J}$ Clin Pharmacol 2006;62:781-92

3. Watts NB. Clinical utility of biochemical markers of bone remodelling. Clin Chem 1999;45:1359-68. 
4. Kurland ES, Cosman F, McMahon DJ, et al. Parathyroid hormone as a therapy for idiopathic osteoporosis in men: effects on bone mineral density and bone markers. $J$ Clin Endocrinol Metab 2000;85:3069-76.

5. Nenonen A, Cheng S, Ivaska KK, et al. Serum TRACP $5 b$ is a useful marker for monitoring alendronate treatment: comparison with other markers of bone turnover. J Bone Miner Res 2005;20:1804-12.

6. Alvarez $L$, Guañabens $\mathbf{N}$, Peris $\mathbf{P}$, et al. Discriminative value of biochemical markers of bone turnover in assessing the activity of Paget's disease. J Bone Miner Res 1995; 10:458-65

7. Bone HG. The future of osteoporosis diagnosis and therapy. Ann Ital Med Int 1992;7(3 Suppl):166-70.

8. Veitch SW, Findlay SC, Hamer AJ, et al. Changes in bone mass and bone turnover following tibial shaft fracture. Osteoporos Int 2006;17:364-72.

9. Hanson DA, Weis MA, Bollen AM, et al. A specific immunoassay for monitoring human bone resorption: quantification of type I collagen cross-linked N-telopeptides in urine. J Bone Miner Res 1992;7:1251-8.

10. Garnero P, Ferreras $\mathbf{M}$, Karsdal MA, et al. The type I collagen fragments ICTP and CTX reveal distinct enzymatic pathways of bone collagen degradation. J Bone Miner Res 2003;18:859-67

11. Stoffel K, Engler H, Kuster M, Riesen W. Changes in biochemical markers after lower limb fractures. Clin Chem 2007;53:131-4.

12. Joerring $\mathbf{S}$, Krogsgaard $\mathbf{M}$, Wilbek $\mathbf{H}$, Jensen LT. Collagen turnover after tibial fractures. Arch Orthop Trauma Surg 1994;113:334-6.

13. Kurdy NM, Bowles S, Marsh DR, Davies A, France M. Serology of collagen types I and III is normal healing of tibial shaft fractures. J Orthop Trauma 1998; 12:122-6.

14. Emami A, Larsson A, Petrén-Mallmin $\mathbf{M}$, Larsson S. Serum bone markers after intramedullary fixed tibial fractures. Clin Orthop 1999;368:220-9.

15. Ohishi T, Takahashi M, Kushida K, et al. Changes in biochemical markers during fracture healing. Arch Orthop Trauma Surg 1998;118:126-30.

16. Karsdal MA, Henriksen K, Sørensen MG, et al. Acidification of the osteoclastic resorption compartment provides insight into the coupling of bone formation to bone resorption. Am J Pathol 2005;166:467-76.

17. Holzer G, Noske H, Lang T, Holzer L, Willinger U. Soluble cathepsin K: a nove marker for the prediction of nontraumatic fractures? Lab Clin Med 2005;146:13-17.

18. Khosla S. Minireview: the OPG/RANKL/RANK system. Endocrinology 2001;142:5050-5.

19. Li J, Sarosi I, Yan X0, et al. RANK is the intrinsic hematopoietic cell surface receptor that controls osteoclastogenesis and regulation of bone mass and calcium metabolism. Proc Natl Acad Sci USA 2000;97:1566-71.

20. Teitelbaum SL, Ross FP. Genetic regulation of osteoclast development and function. Nat Rev Genet 2003;4:638-49.

21. Arai F, Miyamoto T, Ohneda $\mathbf{0}$, et al. Commitment and differentiation of osteoclast precursor cells by the sequential expression of C-Fms and receptor activator of nuclear factor kb (rank) receptors. J Exp Med 1999;190:1741-54.

22. Tanko LB, Mouritzen U, Lehmann HJ, et al. Oral ibandronate: changes in markers of bone turnover during adequately dosed continuous and weekly therapy and during different sub optimally dosed treatment regimens. Bone 2003;32:687-93.

23. Hofbauer LC, Heufelder AE. Role of receptor activator of nuclear factor-kappaB ligand and osteoprotegerin in bone cell biology. J Mol Med 2001;79:243-53.

24. Carter DH, Sloan P, Aaron JE. Immunolocalization of collagen types I and III, tenascin, and fibronectin in intramembranous bone. J Histochem Cytochem 1991;39:599-606

25. Joerring S, Jensen LT, Andersen GR, Johansen JS. Types I and III procollagen extension peptides in serum respond to fracture in humans. Arch Orthop Trauma Surg 1992:11:265-7.
26. Bowles SA, Kurdy N, Davis AM, France MW. Changes in serum bone-specific alkaline phosphatase following tibial fracture. Ann Clin Biochem 1997;34:690-1.

27. Harwood PJ, Giannoudis PV. Application of bone morphogenetic proteins in orthopaedic practice: their efficacy and side effects. Expert Opin Drug Saf 2005;4:75-89.

28. Dimitrou R, Dahabreh Z, Katsoulis $\mathbf{E}$, et al. Application of recombinant BMP-7 on persistent upper and lower limb non-unions. Injury 2005;36(Suppl 4):51-9.

29. Giannoudis PV, Tzioupis C. Clinical applications of BMP-7: the UK perspective. Injury 2005;36(Suppl 3):47-50.

30. Govender S, Csimma C, Genant HK, et al. Recombinant human bone morphogenetic protein-2 for treatment of open tibial fractures: a prospective, controlled, randomized study of four hundred and fifty patients. J Bone Joint Surg [Am] 2002;84-A:2123-34.

31. Ristiniemi J, Flinkkilä T, Hyvönen P, et al. RhBMP-7 accelerates the healing in distal tibial fractures treated by external fixation. J Bone Joint Surg [Br] 2007;89-B:265-72.

32. Ivaska KK, Gerdhem P, Akesson K, Garnero P, Obrant KJ. Effect of fracture on bone turnover markers: a longitudinal study comparing marker levels before and after injury in 113 elderly women. J Bone Miner Res 2007;22:1155-64.

33. Obrant KJ. Trabecular bone changes in the greater trochanter after fracture of the femoral neck. Acta Orthop Scand 1998;55:78-82.

34. Harada S, Rodan GA. Control of osteoblast function and regulation of bone mass Nature 2003;423:349-55

35. Halleen JM. Tartrate-resistant acid phosphatase $5 B$ is a specific and sensitive marker of bone resorption. Anticancer Res 2003;23:1027-9.

36. Halleen JM, Ylipahkala H, Alatalo SL, et al. Serum tartate-resistant acid phosphatase $5 \mathrm{~b}$, but not $5 \mathrm{a}$, correlates with other markers of bone turnover and bone minera density. Calcif Tissue Int 2002;71:20-5.

37. Bradley EW, Oursler MJ. Osteoclast culture and resorption assays. Methods Mol Biol 2008;455:19-35

38. Kim JG, Kim JH, Kim JY, et al. Association between osteoprotegerin (OPG), receptor activator of nuclear factor-kappaB (RANK), and RANK ligand (RANKL) gene polymorphisms and circulating OPG, soluble RANKL levels, and bone mineral density in Korean postmenopausal women. Menopause 2007;14:913-18.

39. Hermann M, Klitscher D, Georg T, et al. Different kinetics of bone markers in normal and delayed fracture healing of long bones. Clin Chem 2002;48:2263-6.

40. Oni 00, Mahabir JP, Iqbal SJ, Gregg PJ. Serum osteocalcin and total alkaline phosphatase levels as prognostic indicators in tibial shaft fractures. Injury 1989;20:37-8.

41. Qvist P, Christgau S, Pedersen BJ, Schlemmer A, Christiansen C. Circadian variation in the serum concentration of C-terminal telopeptide of type I collagen (serum CTX): effects of gender, age, menopausal status, posture, daylight, serum cortisol, and fasting. Bone 2002;31:57-61.

42. Schlemmer A, Hassager $\mathbf{C}$, Alexandersen $\mathbf{P}$, et al. Circadian variation in bone resorption is not related to serum cortisol. Bone 1997;21:83-8.

43. Schlemmer A, Hassager C. Acute fasting diminishes the circadian rhythm of biochemical markers of bone resorption. Eur J Endocrinol 1999;140:332-7.

44. Henriksen DB, Alexandersen $\mathbf{P}$, Byrialsen $\mathbf{I}$, et al. Reduction of nocturnal rise in bone resorption by subcutaneous GLP-2. Bone 2004;34:140-7.

45. Nyman MT, Paavolainen P, Forsius S, Lamberg-Allardt C. Clinical evaluation of fracture healing by serum osteocalcin and alkaline phosphatase. Ann Chir Gynaecol 1991;80:298-93.

46. Chesnut CH III. Sources of biological bone market variability. In: Eastell R, Baumann M Hoyle NR, Wieczorek L, eds. Bone markers: biomechanical and clinical perspectives. London: Martin Dunitz, 2001:119-12.

47. Claudon A, Vergnaud P, Valverde C, et al. New automated multiplex assay for bone turnover markers in osteoporosis. Clin Chem 2008;54:1554-63.

48. Zimmerman $\mathbf{G}$, Henle $\mathbf{P}$, Küsswetter $\mathbf{M}$, et al. TGF-beta1 as a marker of delayed fracture healing. Bone 2005:36:779-85 